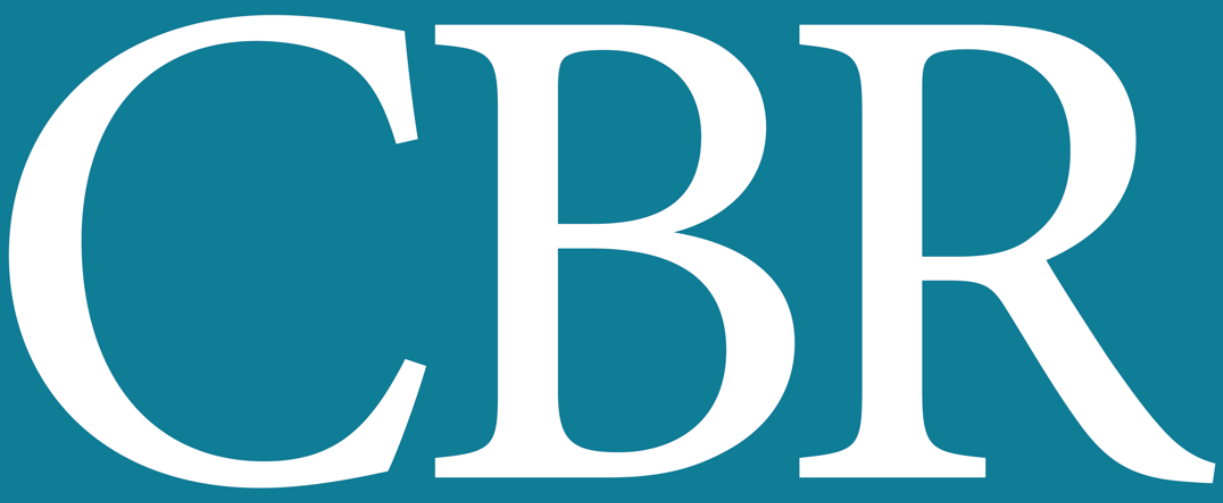

INTERNATIONAL JOURNAL OF CANCER AND BIOMEDICAL RESEARCH

https://jcbr.journals.ekb.eg

Editor-in-chief

Prof. Mohamed Labib Salem, PhD

Factors Affecting Shared Decision-Making in Breast Cancer Surgeries: Egyptian Perspective

Khaled Abdelwahab, Nashwa Ibrahim, Omar Hamdy, Ahmed Abdallah, Amir M Zaid and Mosab Shetiwy 


\section{Welcome letter from Editor-in-Chief}

Welcome to the Int J Cancer and Biomedical Research (IJCBR)!

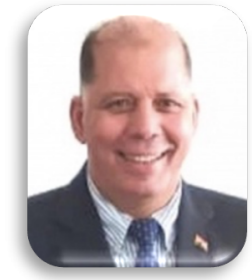

It is with great pleasure that I write this editorial to welcome you to the IJCBR. This journal provides a platform for publication of original and reviews research articles, short communications, letter to editor, thesis abstract, conference report, and case studies. These types of publication are directed at the interface of the fields of cancer and biomedical research.

The IJCBR relies on a distinguished expert of the Advisory and Editorial Board Members from the top international league covering in depth the related topics. They timely review all manuscripts and maintain highest standards of quality and scientific methodology and ethical concepts. Meanwhile, we take all possible means to keep the time of the publication process as short as possible.

I take this chance to welcome your contributions to the IJCBR and have every expectation that it will soon become one of the most respected journals in both the fields of cancer and biomedical research.

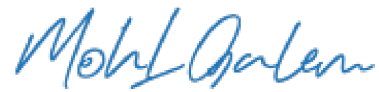

Mohamed L. Salem,

Editor in Chief 


\title{
Factors Affecting Shared Decision-Making in Breast Cancer Surgeries: Egyptian Perspective
}

\author{
Khaled Abdelwahab ${ }^{1}$, Nashwa Ibrahim², Omar Hamdy ${ }^{1}$, Ahmed Abdallah ${ }^{1}$, Amir M Zaid ${ }^{1}$ and Mosab Shetiwy ${ }^{1}$ \\ ${ }^{1}$ Surgical Oncology Unit, Mansoura Oncology Centre, Faculty of Medicine, Mansoura University, Egypt. \\ ${ }^{2}$ Psychiatric and Mental Health Nursing Department, Faculty of Nursing, Mansoura University, Egypt.
}

III

ABSTRACT

Background: Shared decision-making in breast cancer surgeries constitutes interplay between clinicians, patients and family members. More involvement in the decision-making process is associated with high patient satisfaction and better treatment outcomes. Aim: The present study aims to develop the first Arabic questionnaire assessing factors affecting patients' involvement in the decisionmaking of breast cancer surgeries. Methods: A total number of 183 female diagnosed with breast cancer were recruited to participate in the current study. Results: The results revealed that the majority of the current sample were informed about treatment and surgical options available for them. Almost $60 \%$ of women in the current study reported that being married would affect their decision-making process. More than half of the sample reported that their husband opinion matters when it comes to surgical decision making. If breast reconstruction was an available option for women, approximately $57.9 \%$ of them would not prefer it. Nearly three quarters of surgeon participants in the current study reported the need for decisional aids to facilitate engagement of the patients in the decision-making process. additionally, $66.7 \%$ of surgeons reported that patients' comorbidity profile affects engaging them in surgical decision-making. Conclusion: We could conclude that marital status, patients' comorbidity profile, partners' opinion, and the cost of the surgical intervention, age, the social status of the patient, and stage of illness are among the factors that affect shared decision-making.

Keywords: Breast Cancer Surgeries, Decisional Aids, Shared Decision-Making, Patients' Engagement.

Editor-in-Chief: Prof. M.L. Salem, PhD - Article DOI: 10.21608/JCBR.2021.28296.1028
11I ARTICLE INFO

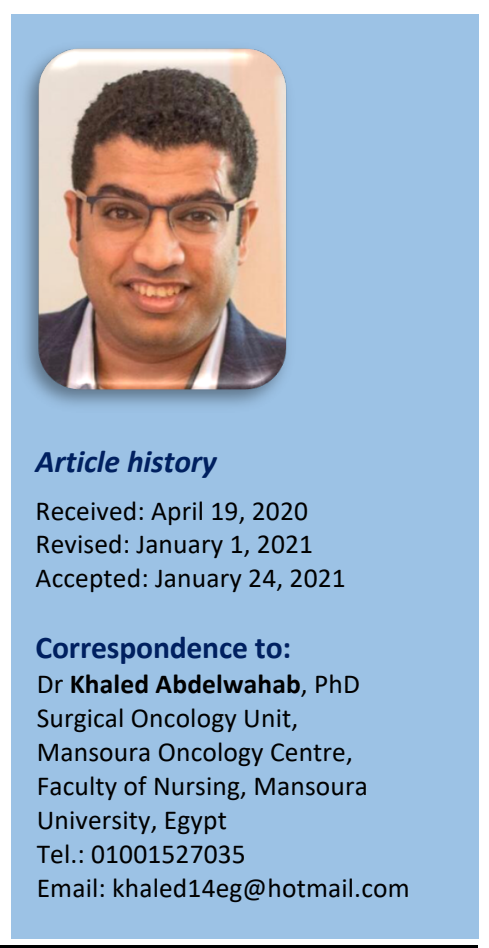

\section{BACKGROUND}

Surgical options for women diagnosed with breast cancer vary from breast-conserving to more aggressive modified radical mastectomy (Lantz et al., 2005). When two or more medically justified treatment options exist, preference-sensitive care should emerge to incorporate sensitively patients' preference to multiple treatment options (Ostermann et al., 2019). Shared decision-making (SDM) involves exchanging information among health care providers, patients, and their family members through an interactive process to enable a shared process to happen (Spatz et al., 2017).

Shared decision-making sheds the light on the over-implementation, under-implementation, and misuse of health care interventions
(Coulter, 2017). Additionally, cost-effectiveness and improved patients' outcomes were associated with SDM (Müller et al., 2019). A systematic review by Joosten et al. (2008) was investigating the impact SDM on patient satisfaction, treatment adherence, and health status. Results of this systematic review reported that shared decision-making is particularly beneficial in the context of chronic illness, long-term decision, and reaching treatment agreement (Joosten et al., 2008).

Egypt enjoys a particular cultural context that affects the SDM process; one of the considerations facing women undergoing breast cancer surgeries in Egypt is their perception of the impact of the surgery on their body image, femininity, and sexuality (Mortada 
et al., 2018). Additionally, women in Egypt usually perceive breast cancer diagnosis as a major threat to their lives (Alagizy et al., 2020). Another essential factor that affects the SDM process is the partner's role in the decisionmaking process. Research reported that male partners of women diagnosed with breast cancer are admitted to hospitals for depression and anxiety (El-Hadidy et al., 2012). Egypt is categorized among "literacy deprived countries" where illiteracy is more prevalent in rural than urban areas. Women constitute nearly $69 \%$ of illiteracy rate in Egypt (Sywelem, 2015). According to Davis et al. (2002), illiterate patients have greater complexity in understanding treatment options as well as difficulty in making appropriate health decisions (Davis et al., 2002). Health policies and research that promote adoption of SDM in health care systems will in return improve the quality and cost of care (Légaré \& Witteman, 2013). In order to capture factors affecting SDM in breast cancer surgeries, we searched for a questionnaire in Arabic language addressing these factors. However, we could not find an existing questionnaire serving this purpose.

The current study aims to develop questionnaire assessing factors affecting engagement of Egyptian female patients in the decision-making of breast cancer surgeries and assess factors affecting engagement of the Egyptian female patients in the decision-making of breast cancer surgeries using the developed questionnaire

\section{METHODS}

Ethical and administrative approvals were obtained prior to commencing with the current study.

\section{To achieve the first aim of the current study (questionnaire development)}

\section{A. Conceptualization phase}

The aim of this stage is to establish domains of the questionnaire (Rattray \& Jones, 2007). Three focus groups (five participants in each) with women admitted for breast cancer surgeries were conducted to generate items and domains of the questionnaire. Women were asked in the focus groups open ended questions about factors affecting their involvement in the decision-making process. Additionally, reading the literature was part of the conceptualization phase of questionnaire.

\section{B. Development phase}

Two main dimensions were generated after the qualitative analysis of the data of the focus groups; patient related factors domains and surgeon related factors domain. For the patient related factors that affect involvement in the decision making process marital status, husband's opinion and consulting another woman who had undergone a similar surgery were among the factors. The second dimension affecting patients' involvement in the decision making process was surgeon related factors (e.g. age and years of experience of the surgeon). Therefore, these factors were integrated and considered in the questionnaire development. Final draft of the questionnaire included; clinical and demographic data section, thirteen items under patient related factors domain and twelve items under surgeon related factors dimension.

\section{Validation phase}

Six breast surgical oncologists were invited to participate in judging the questionnaire. Each item was rated along four-point scale continuum (1 not relevant, 2 somewhat relevant, 3 quite relevant, 4 highly relevant). Items were dichotomized in the analysis into relevant and irrelevant. Four of the breast surgical oncologists rated two items as irrelevant, therefore it was deleted. The overall Content Validity Index (CVI) was 0.83 which reflects adequate and acceptable agreement between breast surgical oncologists (Rubio et al., 2003).

The clarity of the tool was tested with 27 females with a mean age of 50.29 years diagnosed with breast cancer and admitted for breast cancer surgeries. Women were asked to rate each item of the questionnaire as clear or unclear and they were requested to add suggestions if necessary. All participants reported items as clear. Cohen's Kappa was run for patients' related items of the questionnaire in SPSS to determine the level of agreement between two independent assessors (interratter reliability). Kappa ranged from 0.54 to 
0.82 which means moderate to very good agreement (Viera \& Garrett, 2005).

2. Using the developed and validated questionnaire to achieve the second aim of the current study

Through a descriptive cross sectional research designs, a total number of 183 recruited through convenient sampling women diagnosed with breast cancer and admitted for breast cancer surgical interventions at Oncology Centre Mansoura University (OCMU) were invited to participate. No age limit was set for including women in the study. An informed consent was taken from women prior to proceeding with the study. The following formula was used for power analysis:

$$
n=\frac{N \times p(1-p)}{\left[\left[N-1 \times\left(d^{2} \div z^{2}\right)\right]+p(1-p)\right]}
$$

Where $\mathrm{N}$ refers to the population size, $\mathrm{z}=$ degree of freedom for $95 \%$ significance. Absolute precision on either side of the proportion $p(d)=$ error percentage $(0.05)$, and $d=$ the probability of occurrence of the event or not (0.5).

Additionally, a total number of 20 surgeons (the number was decided based on the total number of physicians who are specialised in breast surgeries in the centre) was recruited to participate in surgeon related items of the questionnaire.

\section{Statistical analysis}

For both pilot testing and the larger study, descriptive analysis was conducted: frequency, percent, mean, standard deviation. All data variables were encoded and computerized. Data entry and statistical analysis were performed using the Statistical Package for Social Science (SPSS) version 26 (SPSS Inc., Chicago, Illinois). Categorical data were expressed as number and percentages.

\section{RESULTS}

A total number of 183 females were recruited to participate in the current study. The mean age of the sample was $52.32 \pm 11.86$ years and almost half of the sample (49.2\%) are illiterate, (49.7\%) detected breast cancer through breast self-examination. Table (1) shows participants' characteristics.
Table 1. Participants' characteristics

\begin{tabular}{lll}
\hline & No=183 & \% \\
\hline Marital status & & \\
Single & 4 & 2.2 \\
Married & 154 & 84.2 \\
Divorced & 3 & 1.6 \\
Widow & 22 & 12.0 \\
\hline Educational status & & \\
Illiterate & 90 & 49.2 \\
Primary education & 18 & 9.8 \\
Preparatory education & 14 & 7.7 \\
Secondary education & 51 & 27.9 \\
University degree & 10 & 5.5 \\
\hline Awareness of the diagnosis & & \\
Yes & 171.0 & 93.4 \\
No & 12 & 6.6 \\
\hline Detection of the tumour & & \\
Accidental & 61 & 33.3 \\
breast self-examination & 91 & 49.7 \\
Discharge from the breast & 5 & 2.7 \\
Tender breasts & 16 & 8.7 \\
Breast abscess & 4 & 2.2 \\
& & \\
\hline
\end{tabular}

More than half of the sample were informed about both treatment and surgical options. However, nearly $60 \%$ of women in the sample preferred removing the tumour only over mastectomy and $57.9 \%$ of the sample would not prefer breast reconstruction if it is available as an option.

Surgeons' related items of the questionnaire that affect SDM were collected through selfreports. All surgeons reported engaging patients in surgical decision-making process. However, $93.3 \%$ of them reported difficulty in the engagement process. Additionally, $46.7 \%$ of the surgeons reported that they engage family members of the patients when they find difficulty in the engaging the patient. The other half of the surgeons reported that they simplify information of surgical options as possible to gain patients' engagement.

Regarding factors that affect engagement process; more than half of the surgeons (53.3\%) reported that patients' social level affects engagement process. The majority of surgeons (60.0\%) reported that age of patients and stage of illness affect engagement. The majority of surgeons (66.7\%) reported that patients' comorbidity profile would affect engaging them in surgical decision-making process. 
Table 2. Patients' related factors affecting the SDM

\begin{tabular}{|c|c|c|}
\hline & No=183 & $\%$ \\
\hline $\begin{array}{l}\text { Have you been informed about } \\
\text { available treatment options? Yes }\end{array}$ & 103 & 56.3 \\
\hline No & 80 & 43.7 \\
\hline $\begin{array}{l}\text { Have you been informed about } \\
\text { available surgical options? Yes }\end{array}$ & 108 & 61.9 \\
\hline No & 75 & 38.3 \\
\hline $\begin{array}{l}\text { Does the age of the consulting } \\
\text { surgeon matters when it comes to } \\
\text { choosing from different options? } \\
\text { Yes }\end{array}$ & 55 & 30.1 \\
\hline No & 108 & 59.0 \\
\hline Do not know & 20 & 10.9 \\
\hline $\begin{array}{l}\text { Would you choose removing the } \\
\text { tumour only or total mastectomy } \\
\text { if both options exist for you? } \\
\text { Tumour only }\end{array}$ & 110 & 60.1 \\
\hline Total mastectomy & 52 & 28.4 \\
\hline As my doctor suggests & 13 & 7.1 \\
\hline Do not know & 8 & 4.4 \\
\hline $\begin{array}{l}\text { If breast reconstruction was an } \\
\text { option for you, will you go for it? } \\
\text { Yes }\end{array}$ & 48 & 26.2 \\
\hline No & 106 & 57.9 \\
\hline Will consult my partner & 2 & 1.1 \\
\hline As my doctor suggests & 4 & 2.2 \\
\hline Do not know & 23 & 12.5 \\
\hline $\begin{array}{l}\text { Does being married affects your } \\
\text { surgical choice? Yes }\end{array}$ & 109 & 59.6 \\
\hline No & 63 & 34.4 \\
\hline Do not know & 11 & 6.0 \\
\hline $\begin{array}{l}\text { If breast reconstruction was } \\
\text { available for you, does your } \\
\text { husband opinion matters? Yes }\end{array}$ & 98 & 53.6 \\
\hline No & 59 & 32.2 \\
\hline Do not know & 26 & 14.2 \\
\hline $\begin{array}{l}\text { Have you talked to women who } \\
\text { underwent breast cancer surgeries } \\
\text { before? Yes }\end{array}$ & 86 & 47.0 \\
\hline No & 97 & 53 \\
\hline $\begin{array}{l}\text { If breast surgical interventions } \\
\text { were paid at OCMU, would that } \\
\text { affect your decision Yes }\end{array}$ & 88 & 48.1 \\
\hline No & 70 & 38.3 \\
\hline Do not know & 25 & 13.7 \\
\hline
\end{tabular}

Nearly three quarters of surgeons (73.3\%) reported the need of audio-visual and simplified explanatory aids and materials for patients to facilitate their informative understanding of surgical options as the majority of patients in the current sample are illiterate.

\section{DISCUSSION}

Deciding among treatment options in breast cancer in considered an intense emotionally charged experience for women (Brandzel et al., 2017).
In order to achieve aims of the current study, we developed questionnaire assessing factors affecting SDM in breast cancer surgeries. Items of the questionnaire we developed in the current study correspond with the domains of the Consolidated Framework for Implementation Research (CFIR) that guides multilevel implementation contexts of health research. The domains are the intervention characteristics domain, the inner setting domain, the outer setting domain, characteristics of the individual domain and the implementation process domain (Keith et al., 2017).

Although half of the current sample cannot read and write, $49.7 \%$ of the sample detected breast cancer through breast self-examination. This may be due to awareness campaigns in Egyptian mass media and television that encourage women to do breast-self-examination. This corresponds with Manzour and Gamal Eldin (2019), in the sense that the majority of female participants get their health information from the mass media which is particularly beneficial for people who cannot read and write.

The majority of patients' participants in the current study do not have a preference for breast reconstruction if the option is available for them. Lay people in Egypt consider breast reconstruction as a cosmetic procedure rather than a reconstruction procedure. Women may be scared to underdo another surgical intervention. According to Khan (2018), decisional aids in the form of awareness events for breast reconstruction, offering internet based-information and resources, and helping patients to talk to others who undergone breast reconstruction surgeries are instrumental tool in SDM process. This is consistent with findings of surgeon related items of the questionnaire in the current study as almost three quarters of surgeons reported a need for decisional aids.

More than half of the surgeons in the current study reported patients' social level affects engaging them in the decision making process. Bride et al. (2013), reported that patients' characteristics and background affect their surgical decision. Development of culturally adapted decisional aids (interventions that provide information about health conditions 
and risks and benefits of treatment options to patients) may facilitate patients' engagement in the decision making process (Chenel et al., 2018).

Nearly half of women in the current study reported that husband's opinion matters when it comes to a surgical decision making. In Egypt, many married women are usually scared if they have a serious health problem that their husbands would abandon them or even marry another woman. Female breasts are linked to women femininity, sexuality and body image. According to Martino and Freda (2016), response to changes after treatment are culturally linked to how each culture gives meaning to health and alteration in health status.

Data from this study was recruited from single institution which may be considered a limitation of the current study. The lack of randomisation in sampling is a limitation in the current study.

\section{CONCLUSION}

Results of the current study conclude that marital status, patients' comorbidity profile, partners' opinion, and the cost of the surgical intervention, age, the social status of the patient, and stage of illness are among the factors that affect SDM process.

\section{IMPLICATIONS FOR PRACTICE}

Based on results of the current study, an intervention can be developed aiming at facilitating engagement of Egyptian female patients in the decision making of breast cancer surgeries for example development of patients' sensitive and culturally adapted decisional aids.

\section{ACKNOWLEDGEMENT}

We are grateful to all women who had participated in this study, additionally we thank Dr Mohamed Zromba for his help in the validation phase of the questionnaire.

\section{LIST OF ABBREVIATIONS}

Shared Decision Making= SDM

Content Validity Index $=\mathrm{CV}$ I

Consolidated Framework for Implementation Research $=$ CFIR

\section{CONFLICTS OF INTEREST}

All authors have approved this article and declare no conflicts of interest.

\section{FUNDING}

This research hasn't received a fund.

\section{REFERENCES}

Alagizy, H. A., Soltan, M. R., Soliman, S. S., Hegazy, N. N., \& Gohar, S. F. (2020). Anxiety, depression and perceived stress among breast cancer patients: single institute experience. Middle East Current Psychiatry, 27(1), 1-10.

Brandzel, S., Rosenberg, D. E., Johnson, D., Bush, M., Kerlikowske, K., Onega, T., ... \& Wernli, K. J. (2017). Women's experiences and preferences regarding breast imaging after completing breast cancer treatment. Patient preference and adherence, 11, 199.

Bride, M. B. M., Neal, L., Dilaveri, C. A., Sandhu, N. P., Hieken, T. J., Ghosh, K., \& Wahner-Roedler, D. L. (2013). Factors associated with surgical decision making in women with early-stage breast cancer: a literature review. Journal of women's health, 22(3), 236-242

Chenel V, Mortenson W. B., Guay M, Jutai J. W., \& Auger, C. (2018). Cultural adaptation and validation of patient decision aids: a scoping review. Patient preference and adherence, 12, 321-332. doi: 10.2147/PPA.S151833

Coulter A. (2017). Choosing wisely: learning from international experience. Gütersloh: Bertelsmann Stiftung, 1-40.

Davis, T. C., Williams, M. V., Marin, E., Parker, R. M., \& Glass, J. (2002). Health literacy and cancer communication. CA: a cancer journal for clinicians, 52(3), 134-149.

El-Hadidy, M. A., Elnahas, W., Hegazy, M. A., Hafez, M. T., Refky, B., Wahab, K. M. A. J. B. C. T., \& Therapy. (2012). Psychiatric morbidity among Egyptian breast cancer patients and their partners and its impact on surgical decisionmaking. 4, 25.

Joosten, E. A., DeFuentes-Merillas, L., De Weert, G. H., Sensky, T., Van Der Staak, C. P. F., \& de Jong, C. A. (2008). Systematic review of the effects of shared decision-making on patient satisfaction, treatment adherence and health status. Psychotherapy and psychosomatics, 77(4), 219-226.

Keith, R. E., Crosson, J. C., O'Malley, A. S., Cromp, D., \& Taylor, E. F. (2017). Using the Consolidated Framework for Implementation Research (CFIR) to produce actionable findings: a rapid-cycle evaluation approach to improving 
implementation. Implementation

Science, 12(1), 15.

Khan, H. (2018). Decisional Conflict in Women with Newly Diagnosed Breast Cancer Seeking Breast Reconstruction Surgery: A Pilot Study (Doctoral dissertation, Carlow University).

Lantz, P. M., Janz, N. K., Fagerlin, A., Schwartz, K., Liu, L., Lakhani, I., ... \& Katz, S. J. (2005). Satisfaction with surgery outcomes and the decision process in a population-based sample of women with breast cancer. Health services research, 40(3), 745-768

Légaré, F., \& Witteman, H. O. (2013). Shared decision making: examining key elements and barriers to adoption into routine clinical practice. Health affairs, 32(2), 276-284.

Galal, Y. S., Emadeldin, M., \& Mwafy, M. A. (2019). Prevalence and correlates of bullying and victimization among school students in rural Egypt. Journal of the Egyptian Public Health Association, 94(1), 18.

Martino, M. L., \& Freda, M. F. J. E. s. j. o. p. (2016). Meaning-making process related to temporality during breast cancer traumatic experience: The clinical use of narrative to promote a new continuity of life. 12(4), 622.

Mortada, E. M., Salem, R. A., Elseifi, O. S., \& Khalil, O. M. J. J. o. C. H. (2018). Comparing HealthRelated Quality of Life among Breast Cancer Patients Receiving Different Plans of Treatment, Egypt. 43(6), 1183-1191.
Müller, E., Strukava, A., Scholl, I., Härter, M., Diouf, N. T., Légaré, F., \& Buchholz, A. (2019). Strategies to evaluate healthcare provider trainings in shared decision-making (SDM): a systematic review of evaluation studies. BMJ open, 9(6), e026488.

Ostermann, J., Brown, D. S., van Til, J. A., Bansback, N., Légaré, F., Marshall, D. A., \& Bewtra, M. (2019). Support Tools for Preference-Sensitive Decisions in Healthcare: Where Are We? Where Do We Go? How Do We Get There?. The Patient-Patient-Centered

Outcomes Research, 12(5), 439-443.

Rattray, J., \& Jones, M. C. (2007). Essential elements of questionnaire design and development. Journal of clinical nursing, 16(2), 234-243.

Rubio, D. M., Berg-Weger, M., Tebb, S. S., Lee, E. S., \& Rauch, S. J. S. W. r. (2003). Objectifying content validity: Conducting a content validity study in social work research. 27(2), 94-104.

Spatz, E. S., Krumholz, H. M., \& Moulton, B. W. J. J. (2017). Prime time for shared decision making. 317(13), 1309-1310.

Sywelem, M. M. G. (2015). Literacy and adult education in Egypt: achievements and challenges. American Journal of Educational Research, 3(7), 793-799.

Viera, A. J., \& Garrett, J. M. (2005). Understanding inter-observer agreement: the kappa statistic. Fam med, 37(5), 360-363. 


\section{Egyptian Association for Cancer Research (EACR)}

http://eacr.tanta.edu.eg/

EACR is an NGO society that was declared by the Ministry of Social Solidarity (Egypt) No. 1938 in 19/11/2014 based on the initiative of Prof. Mohamed Labib Salem, the current Chairman of EACR. EACR aims primarily to assist researchers, in particular young researchers in the field of cancer research through workshops, seminars and conferences. Its first international annual conference entitled "Anti-Cancer Drug Discovery" was successfully organized in April 2019 (http://acdd.tanta.edu.eg). Additionally, EACR aims to raise the awareness of the society about the importance of scientific research in the field of cancer research in prediction, early diagnosis and treatment of cancer. EACR is also keen to outreach the scientific community with periodicals and news on cancer research including peer-reviewed scientific journals for the publication of cutting-edge research. The official scientific journal of EACR is "International Journal of Cancer and biomedical Research (IJCBR: https://jcbr.journals.ekb.eg) was successfully issued in 2017 and has been sponsored by the Egyptian Knowledge Bank (EKB: www.ekb.eg).

\section{EACR Chairman,}

Prof. Mohamed Labib Salem, PhD

Professor of Immunology

Faculty of Science, Tanta Universiy, Egypt 
International Journal of Cancer and Biomedical Research (IJCBR), a publication of the Egyptian Association for Cancer Research (EACR), is a peer-reviewed online journal published quarterly. The journal allows free access (Open Access) to its contents and permits authors to self-archive a final accepted version of the articles on any OAl-compliant institutional / subject-based repository.

\section{Aim And Scope}

Aim: The main aim of IJCBR is to attract the best research in animal and human biology in health and diseases from across the spectrum of the biomedical sciences at the molecular, cellular, organ, and whole animal levels especially those that are related to cancer research, including causes, prediction, diagnosis, prognosis and therapy.

Scope: It is essential reading for all researchers interested in biochemistry, cancer, microbiology, nutrition, physiology, genetics, immunology, epidemiology, medical economics, human biology, bioinformatics, biotechnology, nanotechnology, and disease modeling.

\section{Publication Ethics}

Researchers should conduct their research from research proposal to publication in line with the best practices and codes of conduct of relevant professional bodies and/or national and international regulatory bodies. IJCBR accepts manuscripts prepared in accordance with the "Uniform Requirements for Submission of Manuscripts for Biomedical Journals adopted by the International Committee of Medical Journal Editors (ICMJE) and the Committee on Publication Ethics (COPE). Details of ICMJE and COPE are available at http://www.icmje.org/ and http://publicationethics.org/

\section{Peer Review Process}

After the IJCBR editor receives a manuscript, the first step is to confirm that the manuscript meets the journal's rules for content and format, including similarity check (plagiarism) which should be less than $25 \%$. If the manuscript meets the journal's rules, the editor then assign it to the double-blind peer review process. The IJCBR editor send the manuscript to at least two experts in the field for RIGOROUS scientific evaluation. The experts called peer reviewers - will then prepare a report that assesses the manuscript and return it to the editor through the IJCBR portal. Upon the first submission, this reviewing process takes about 4 to 6 weeks. After reading the peer reviewer's report, the editor will decide one of the following four options:

1. Reject the manuscript.

2. Accept the manuscript

3. Ask the authors to revise and resubmit the manuscript after responding to the peer reviewers' feedback.

4. Ask for peer-review from additional reviewers.

If the authors resubmit the manuscript, the IJCBR editor will ask the same peer-reviewers to look over the manuscript again to confirm that their concerns have been addressed. This is called re-review process. This second revision (if applicable) takes about another 4 to 6 weeks. At this point, the abstract of the article appears in press. The online publication (the PDF format) of the final version of the manuscript takes from 2 to 4 weeks. As such, the total publication cycle takes from 2 to 4 months. This cycle can be reduced to 4 to 6 weeks (fast track publication) for the manuscripts with outstanding findings.

The peer-review process used by IJCBR includes comments on errors in the study's methods or analysis that raise questions about the findings, or sections that need clearer explanations. The peer-review process also includes the importance and novelty of the manuscript and its interest to the journal's audience. The IJCBR uses double-blind review, which means that both the reviewers and authors identities are concealed from the reviewers, and vice versa, throughout the review process. To facilitate this, authors need to submit a Title Page containing the Authors details and Blinded Manuscript with no author details as 2 separate files. 


\section{Publisher}

The International Journal of Cancer and Biomedical Research (IJCBR) is an International and interdisciplinary journal of preclinical and clinical studies in the area of cancer and biomedical research. It is a peer-reviewed journal in English, published quarterly (in March, June, September, and December) by the Egyptian Association for Cancer Research (EACR) in both print and online formats (4 issues making a volume). Special issues or supplements may also be produced from time to time upon agreement with the Editorial Board.

\section{Scope}

The main aim of IJCBR is to attract the best research in animal and human biology in health and diseases from across the spectrum of the biomedical sciences at the molecular, cellular, organ, and whole animal levels especially those that are related to cancer research, including causes, prediction, diagnosis, prognosis and therapy.

\section{Publication Fees}

The journal does charge for submission, processing or publication of manuscripts (2000 LE for Egyptians or $\$ 300$ for non-Egyptians; EACR members receive 15\% discount on publication). Of them Peer-review fees (300 LE) should be paid on submission (non-refundable). For the fast track production of the accepted manuscript, another $500 \mathrm{LE}$ is paid.

General specifications for different types of article

- Submitted manuscripts should not have been published previously, except in a limited form (e.g. short communication to a symposium or as part of MSc or PhD theses) and should not be under consideration for publication by other journals.

- All co-authors should agree with the content of the manuscript. Authors must have obtained permission to use any copyrighted material in the manuscript before submission.

\section{IJCBR publishes different types of articles}

- Original Article (6000 words with $\mathbf{4}$ tables and $\mathbf{4}$ figures, maximum $\mathbf{8}$ display items): Articles with novel findings are the target of IJCBR. Articles presenting a detailed description of a new technique, comparison of existing methods, meta-analyses with comprehensive and in-depth discussion are considered. Papers in a numbered series are not accepted unless all are submitted at the same time.

- Short communications or case study (3000 words with 4 display items): Short communications present exceptionally exciting, novel or timely contents are considered. They will be peer-reviewed in the same way as research papers. The references are restricted to 15 .

- Reviews or systematic review (9000 words with $\mathbf{1 0}$ display items): They are invited by the Editorial Board or unsolicited. Review articles have to be contemporary and comprehensive and add information to the knowledge. Sharp critical analyses of novel data or concepts are encouraged. When relevant, a statistical analysis of data and a meta-analysis approach are recommended.

- Opinion papers, letter to the editor or comment to the editor (1500 words with $\mathbf{2}$ display items): They are submitted by invitation of the Editorial Board. They are short papers, which aim to inform scientists, industry, and the public and policymakers about cutting-edge issues in research or the impact of research. They reflect the opinion of their authors who bear full responsibility of the published paper. The references are restricted to 10 .

- Conference/Symposium papers: The journal will consider for publication the results of original work and critical reviews that are presented at conferences/symposia. Symposium organizers who wish to publish bundles of papers from a symposium/conference in IJCBR should first contact the Editor-inChief of the IJCBR (EACR@unv.tanta.edu.eg) for agreement. Supplementary material can be proposed and will be made available online. The responsibility for the preparation of a paper in a form suitable for publication lies with the author.

- Thesis: IJCBR can publish the summary and abstract of Master and PhD theses in a special issue. 
English: Good quality of written English is required. Spelling may be in British or American English but must be consistent throughout the paper. Care should be exercised in the use of biological terminology that is ill-defined or of local familiarity only. We recommend that authors have their manuscripts checked by an English language native speaker before submission.

Manuscript layout: Manuscripts should be prepared using a standard word processing program and presented in a clear readable format with easily identified sections and headings. The manuscript layout is based on the following directions.

- The main text contains Title, Abstract, Keywords, Introduction, Material and Methods, Results, Discussion, References, Tables, figures.

- The title needs to be concise and informative. Use bold, with an initial capital for the first word only and for words that ordinarily take capitals

- Short (running) title (max 80 characters including spacing).

- The article text should be typed with double-line spacing with wide margins $(2.5 \mathrm{~cm})$.

- The lines must be continuously numbered; the pages must also be numbered.

- Font Calibri 12 should be used for the text, and 12 for the tables, figure legends and references.

- The sections should typically be assembled in the following order:

- Title page contains title, authors' names, full affiliations, acknowledgements and the corresponding author's contacts and Short title.

Abstract (max 250 words, single paragraph): The abstract should be complete and understandable without citation, references, table or figure. Use structured abstract: Background, Aim, Materials \& Methods, Results and Conclusion. The context and the rationale of the study are presented succinctly to support the objectives. The experimental methods and main results are summarized but should not be overburdened by numerical values or probability values. The abstract ends with a short and clear conclusion.

Keywords: Up to five short and specific keywords should complement the title with respect to indicating the subject of the paper in alphabetic order.

Introduction: The introduction briefly outlines the context of the work, presents the current issues that the authors are addressing and the rationale to support the objectives, and clearly defines the objectives.

Material and methods: Material and methods should be described in sufficient details so that others can repeat the experiment. Reference to previously published work may be used to give methodological details, provided that said publications are readily accessible and in English. The code of ethics should be followed for all experiments use animals or human samples.

Statistical analysis of results: The statistical design and the models of statistical analysis must be described, as well as each of the statistical methods used. Sufficient statistical details must be given to allow replication of the statistical analysis. The experimental unit should be defined (e.g. individual or group of animals).

Results: Data are presented as tables and figures. Brief description of the results for each table and figure should be presented. Unpublished data can be mentioned when necessary.

Discussion: Should be separate from the Results section and should focus only on intra- and inter-data discussion (the data in the results section) as well as with the relative data in the literature. Don't repeat information already presented in the Introduction section. Start the first paragraph in the Discussion with a paragraph stating the rationale behind the study, the objectives and the main findings. End Discussion with a short conclusion.

Acknowledgements: In this section, the authors may acknowledge (briefly) their support staff.

Conflict of interest: All papers with a potential conflict of interest must include a description/explanation in a separate heading.

Funding details: The authors should state the source of findings of the study (with research funder and/or grant number). If no fund, the authors should state that the study is self-funded. 


\section{References}

Citation of references: In the text, references should be cited by the author(s) surname(s) and the year of publication (e.g. Salem, 2020). References with two authors should be cited with both surnames (e.g. Salem and Meshrif, 2021). References with three or more authors should be cited with the first author followed by et al. (in italics; e.g. Salem et al., 2021). Names of organizations used as authors (e.g. Food and Drug Administration) should be written out in full in the list of references and on the first mention in the text. Subsequent mentions may be abbreviated (e.g. FDA).

- List of references. Literature cited should be listed in alphabetical order by authors' names. It is the author's responsibility to ensure that all references are correct. All authors should be written and so the full journal name.

- References from journal articles are formatted in APA as this example: Al-Amoudi WM (2018). Toxic effects of Lambda-cyhalothrin on the rat thyroid. Involvement of oxidative stress and ameliorative effect of ginger extract. Toxicology Reports, 5: 728-736.

- References from books or official reports are formatted as this example. Kebreab E, Dijkstra ANM, Bannink A, Gerrits WJJ, \& France J (2006). Nutrient digestion and utilization in farm animals. CABI Publishing. Wallingford, UK.

- References from chapters or parts of books are formatted as this example. Nozière $P, \&$ Hoch $T$ (2006). Modelling fluxes of volatile fatty acids from rumen to portal blood. In: Nutrient digestion and utilization in farm animals (Kebreab E, Dijkstra ANM, Bannink A, Gerrits WJJ \& France J, eds.), pp. 40-47. CABI Publishing. Wallingford, UK.

Tables:

The data should be presented in tables or in graphs, not both.

- Each table should be placed on a separate page at the end of the main text.

- Tables are numbered consecutively using Arabic numbering. They are referred to as Table 1 , Table 2, etc., with capital ' $T$ ', no italics

- Each table has its explanatory caption. The caption is sufficient to permit the table to be understood without reference to the text.

- Abbreviations used in tables/figures have to be defined either as footnotes or in the caption.

Figures

- Package the figures in a single PowerPoint file. Each figure in a separate slide.

- Figure size should be readable in a width of approximately 8-175 $\mathrm{mm}$ (i.e. the maximum size of printing over two columns).

- Ensure that the font size is large enough to be readable at the final print size, use Calibri font to ensure that they are consistent throughout the figures.

- The figures should preferably be provided as TIFF or EPS files.

- The resolutions of figures must be at least $300 \mathrm{dpi}$.

- Preparation of images for a manuscript: For guidance, we refer to the Journal of Cell Biology's instructions to authors (http://jcb.rupress.org/site/misc/ifora.xhtml\#image_aquisition).

- If a cropped image is included in the main text of a paper (e.g. a few lanes of a gel), display the full original image, including the appropriate controls, the molecular size ladder and/or the scale as relevant, as a single figure in a Supplementary Material file to facilitate peer-review and for subsequent online publication.

- Supplementary material is submitted along with the main manuscript in a separate file and identified at uploading as "Supplementary File - for Online Publication Only" The title of the article is included at the top of the supplementary material.

Corresponding author's guidelines: Upon acceptance the corresponding author is required to send his/her recent formal photo to be attached to the front page of the article. 


\title{
International Journal of Cancer \& Biomedical Research
}

(IJCBR) Online ISSN 2682-2628

\author{
Editor-in-Chief \\ Mohamed Labib Salem, PhD \\ Tanta University, Egypt
}

\begin{tabular}{l} 
EACR Board \\
\hline Nehal Elmashad, MD \\
Tanta University, Egypt \\
Nabil Mohy Eldin, PhD \\
Kafrelsheikh University, Egypt \\
Doaa Al-Ghareeb, PhD \\
Alexandria University, Egypt \\
Abdel-Aziz Zidan, PhD \\
Damanhour University, Egypt
\end{tabular}

\begin{tabular}{l} 
Managing Editor \\
\hline Wesam Meshrif, PhD \\
Tanta University, Egypt \\
Sohaila Galal, PhD \\
Tanta University, Egypt \\
Production and Contact \\
\hline Hamdi Kandil \\
Tanta University, Egypt \\
Email: ljcbr100@gmail.com
\end{tabular}

\section{Advisory Board}

Alberto Montero, MD

Taussig Cancer Center, Cleveland,

USA

Yi Zhang, MD

Zhengzhou University, China

Mark Robunstein, Ph D

Medical University of South

Carolina, USA

Mohsen Farid, Ph D

Derby University, USA

Natarajan Muthusamy, Ph D

Ohio State University, USA

Hideki Kasuya, MD

Nagoya University, Japan

Sherif El-Khamisy, Ph D

Sheffield University, UK

Mohamed Ghanem, Ph D

Kafr Elshikh University, Egypt

Sayed Bakry, Ph D

Alazhar University, Egypt

Sameh Ali, Ph D

Nationa Liver Institute, Egypt

Gamal Badr, Ph D

Assuit University, Egypt

Nadia Hamdy, Pharm D

Ain Shams University, Egypt

\section{Editorial Board}

\section{Clinical studies}

Hesham Tawfik, MD

Tanta University, Egypt

Mohamed Attia, MD

Tanta University, Egypt

Mohamed Elshanshory, MD

Tanta University, Egypt

Essam Elshiekh, MD

Tanta Cancer Center, Egypt

Rasha Eraky, MD

Tanta University, Egypt

Shaima Abou-Kjatwa, MD

Tanta University, Egypt

Marcela Diaz, MD

Cleveland Clinic Foundation, USA

Mohamed Abou-El-Enein, MD

Charité Universitätsmedizin Berlin,

Germany
Alaa Eldin Almostafa, MD

McGill University, Canada

Olfat Gadallah, MD

Tanta University, Egypt

Nagla Sarhan, MD

Tanta University, Egypt

Naglaa Fathy, Pharm D

Zagazik University, Egypt

Mohamed Salama, MD

Mansoura University, Egypt

Mona Marie, MD

Alexandria University, Egypt

Preclinical studies

Mostafa El-Sheekh

Tanta University, Egypt

El-Refai Kenawy, Ph D

Tanta University, Egypt

Mohamed Noureldin, Ph D

Banaha University, Egypt

Yousry Albolkiny, Ph D

Tanta University, Egypt

Elsayed Salim, Ph D

Tanta University, Egypt

Shengdian Wang, Ph D

Chinese Academy of Sciences,

China

Sabry El Naggar, Ph D

Tnata Univesity, Egypr

Faris Alenzi, Ph D

Prince Sattam bin Abdulaziz

University, KSA

Ibrahim El-Sayed, Ph D

Menoufia University, Egypt

Tarek Aboul-Fadl, Ph D

Assiut University, Egypt

Rabab Khairat, Ph D

National Research Center,

Giza, Egypt

Wael Lotfy, Ph D

Alexandria University, Egypt

Ashraf Tabll, Ph D

National Research Center, Egypt

Nahla Shoukry, Ph D

Suez University, Egypt
Medhat Eldenary, Ph D

Tanta University, Egypt

Azza Hasan, Ph D

Menufia University, Egypt

Nanees Gamal Eldin, Ph D

Tanta University, Egypt

Mohamed Mansour, UK

Sabbah Hammoury, Ph D

Alexandria Ayadi Almostaqba

Oncology Hospital, Egypt

Nehal Aboulfotoh, Ph D

Zewail City for Science and

Technology, Cairo, Egypt

Amir Elkhami, Ph D

Galaxo, San Francisco, USA

Ahmed Alzohairy, Ph D

Zagazi University, Egypt

Wgady Khalil, Ph D

National Research Center, Egypt

Amr Amin, Ph D

United Arab Emirates

University, UAE

AbdelRahman Zekri, Ph D

National Cancer Institute, Egypt

Hussein Khamis, Ph D

Alexandria University, Egypt

Magdy Mahfouz, Ph D

Kafr Elsheikh University, Egypt

Ehab Elbedewey, Ph D

Tanta University, Egypt

Abeer Badr, Ph D

Cairo University, Egypt

Mamdooh Ghoneum, Ph D

Charles Drew University of

Medicine \& Science, USA

Haiam Abou Elela, Ph D

National Institute of Oceanography and Fisherie, Egypt

Maha EL-Demellawi, Ph D City for Scientific Research \&

Technology Applications, Egypt

Desouky Abd-El-Haleem, Ph D

City for Scientific Research \&

Technology Applications, Egypt 